Journal of Teacher Education for Sustainability, vol. 19, no. 2, pp. 165-179, 2017

\title{
Factors Determining Children and Young People's Well-being at School
}

\author{
Anita Stasulane \\ Daugavpils University, Latvia
}

\begin{abstract}
The article addresses the issue of children and young people's well-being at school. The issue has been known as topical for already some time. In recent decades, in order to be able to determine the true nature and essence of the phenomenon of well-being, the necessity to find the ways for identification of children and young people's self-assessment of well-being at school has become very important. There are many challenges related to conducting new longitudinal studies on children and young people's well-being. The phenomenon of well-being at school cannot be seen only in the context of local situation; it is deeply contextual. Its essence is also determined by the content and values that have emerged in the development of wider global or regional relations and attitudes. Therefore, for the formation of a broader perspective of the article, such phenomena as sustainability and unsustainability were used. This made it possible to refer to the trends of sustainability and unsustainability that had long been highlighted in the studies of global development and education. The analysis of the phenomenon of well-being at school is offered based on the research results within EU FP7 project "Measuring Youth Well Being" (MYWeB) that took a balanced approach to assessing the feasibility of a European Longitudinal Study for Children and Young People through prioritising both scientific and policy imperatives and was carried out in cooperation with eleven European countries. The aim of the article in accordance with one of the specific tasks of the project is to find out the meaning and significance that children and young people allocate to well-being. The article discusses one of the most relevant domains of wellbeing - school, and how it relates to happiness, life-satisfaction and psychological wellbeing of children and young people. The article outlines the results of fieldwork undertaken in project consortium countries (Croatia, Estonia, Georgia, Germany, Greece, Hungary, Latvia, Portugal, Slovakia, Spain, and the United Kingdom) with the goal to understand the subjective experiences of children and young people from different age groups, regions and socio-economic backgrounds. The results of the research confirmed that educational spaces could take a more significant role in promoting well-being of children and young people; in its turn, the education system must rebalance academic learning and emotional well-being.
\end{abstract}

Keywords: well-being, domains of well-being, longitudinal study, school, education sustainability and unsustainability 


\section{Introduction: Understanding of Well-Being}

Sustainable well-being is one of the basic human needs. Currently the issue of making children and young people's well-being sustainable has become a goal of public organisations worldwide, i.e., well-being and sustainability have come together on a global scale and raised two questions. The first question is how we can provide good well-being to children and young people. The second question is how we can provide intergenerational equity, i.e., how to meet the needs of the present without compromising the ability of future generations to meet their own needs. The principle of sustainability represents a key issue to address these questions.

It can be argued that well-being is supposed to be a central element of sustainable development of children and young people. Since education helps a person to gain his/ her place in society, school is particularly correlated with well-being. A recent body of literature in education shreds some light on reorientation of school towards the aim of sustainable development (Salite et. al, 2016). The European network of the Baltic and Black See Circle Consortium (BBCC) has experience in education research for sustainable development and proposes a concept of mission oriented pedagogy which "helps to reflect those cases when pedagogy and educators have not lost the highest humane ideals and the function of searching for sustainability which is characteristic to pedagogy" (Salite, 2015, p. 27). The BBCC has created an open transdisciplinary research framework and a strategic vision that will help reorient education to sustainable development, i.e., to the main component of children and young people's well-being.

An academic debate has emerged about the nature of well-being in philosophy and its measurement in sociology (Van der Deijl, 2017). Since well-being has captured and continues to capture academic and policy interest over the decades, it comes as a surprise that there is no universally accepted definition of the concept. The term well-being is used as an "over-arching concept to refer to the quality of life of people in society" (Rees et al., 2010, p. 8). In defining the concept of well-being, a distinction is also made between the hedonic and eudaimonic approaches (Ryan \& Deci, 2001; Keyes, Shmotkin, \& Ryff, 2002). Hedonic approach is commonly understood as subjective happiness and the experience that increased pleasure and decreased pain leading to happiness. Between many ways to evaluate the pleasure and pain continuum, researchers have used mainly assessment of subjective well-being (Diener \& Lucas, 1999). The subjective well-being consists of three components: life satisfaction, high levels of positive affect and low levels of negative affect, together often summarized as happiness. It is worth noting that a high level of subjective well-being is not assumed to develop from the absence of negative mood, but from a positive balance of negative and positive mood (Fredrickson $\&$ Losada, 2005; Huppert \& So, 2013). In other words, the hedonic well-being has been proposed to consist of positive affect, negative affect, and life satisfaction (Diener, Suh, Lucas, \& Smith, 1999).

The eudaimonic approach in its turn is conceptualized as the outcome of positive goal pursuits (Ryan, Huta, \& Deci, 2006). This approach maintains that not all desires, i.e., not all outcomes that a person might value, would yield well-being when achieved (Ryan \& Deci, 2001). Focusing on meaning and self-realisation, the eudaimonic approach is made up of six elements: autonomy, environmental mastery, personal growth, positive relations with others, purpose in life, and self-acceptance (Ryff, 1989). Ryff and Singer $(1998,2000)$ have explored the question of well-being in the context of developing a lifespan theory of human flourishing. Self-determination theory (Ryan \& Deci, 2000) is 
another perspective that has both embraced the concept of eudaimonia, or self-realisation, as a central definitional aspect of well-being and attempted to specify both what it means to actualize the self and how that can be accomplished. Specifically, self-determination theory posits three basic psychological needs (autonomy, competence, and relatedness) and theorises that fulfilment of these needs is essential for psychological growth (e.g., intrinsic motivation), integrity (e.g., internalisation and assimilation of cultural practices), and well-being (e.g., life satisfaction and psychological health) (Ryan \& Deci, 2001).

Although there is much debate among the followers of these two approaches, evidence from a number of investigators (e.g., Biswas-Diener, Kashdan, \& King, 2009; Compton et al., 1996; King \& Napa, 1998; McGregor \& Little, 1998; Proctor, Tweed, \& Morris, 2014) has indicated that well-being is probably best conceived as a multidimensional phenomenon that includes aspects of both the hedonic and eudaimonic conceptions of well-being.

In the EU FP7 project “Measuring Youth Well Being” (MYWeB), we undertook a holistic approach focusing on both hedonic and eudaimonic aspects of well-being. In other words, we explored the psychological, affective (both positive and negative), and cognitive aspects (life satisfaction and its domain specific satisfaction) of well-being. It is argued that the affective aspect of well-being is less stable over time because of its reliance on people's experience of positive and negative emotions, which typically varies over time. However, people's evaluations of their overall (life satisfaction) or particular aspects of their life (domain satisfaction) are thought to be more stable over time (Rees et al., 2013). We carefully considered this important measurement aspect in our research because we were about to test the possibility of measuring children's well-being over a period of time for which we will need a stable and reliable measure.

\section{Fieldwork Characteristics}

The aim of the fieldwork was to understand the subjective experiences of children and young people from different age groups, regions and socio-economic backgrounds. It served to take into consideration the views and opinions of children and young people on their understanding of well-being and its different dimensions. The field research was conducted using qualitative methods. Two instruments were used in the data collection: the first was individual interviews: researchers worked by focusing on children and young people's daily lives and listening to their stories. The second was the focus group discussion for which a moderation guide was used by researchers.

The fieldwork was conducted in Croatia, Estonia, Georgia, Germany, Greece, Hungary, Latvia, Portugal, Slovakia, Spain, and the United Kingdom. The timing of the fieldwork was between October 2014 and January 2015. There was variation in the following characteristics of children and young people: age, gender, social background, political and civic engagement of young people, family situation, nationality/place of birth, personal characteristics such as a disability or dyslexia, type of school and the place of residence. The age of the respondents was mainly between 11 and 18 years, including some particular cases of younger children ( 9 or 10 years) or exceptionally, some older young people (21 years old at the maximum). Figure 1 below summarises the number of individual interviews and focus group discussions held, number of the participants, and the characteristics of the participants by gender for each country and in total. 
Figure 1

Fieldwork Characteristics

\begin{tabular}{|c|c|c|c|c|c|c|c|c|c|c|c|}
\hline \multirow[b]{2}{*}{ Countries } & \multicolumn{4}{|c|}{ Interviews } & \multicolumn{4}{|c|}{$\begin{array}{c}\text { Focus Groups } \\
\text { (number of participants) }\end{array}$} & \multirow[b]{2}{*}{$\begin{array}{c}\text { Total } \\
\text { CYP } \\
\text { involved }\end{array}$} & \multicolumn{2}{|c|}{ Gender } \\
\hline &  & $\stackrel{:}{\stackrel{\Xi}{\Xi}}$ & 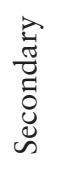 & : & 仼 & 鴶 & 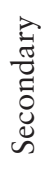 & 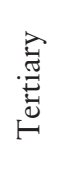 & & 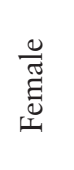 & $\frac{\stackrel{0}{\pi}}{\sum}$ \\
\hline Croatia & 21 & 5 & 5 & 11 & 4 & 10 & 9 & 11 & 51 & 24 & 27 \\
\hline Estonia & 21 & 10 & 7 & 4 & 4 & 5 & 6 & 10 & 42 & 21 & 21 \\
\hline Georgia & 20 & 5 & 5 & 10 & 4 & 9 & 5 & 11 & 45 & 21 & 24 \\
\hline Germany & 18 & 3 & 5 & 10 & 3 & - & 5 & 8 & 31 & 18 & 13 \\
\hline Greece & 21 & 6 & 5 & 10 & 4 & 7 & 7 & 10 & 45 & 28 & 17 \\
\hline Hungary & 20 & 5 & 6 & 9 & 4 & 3 & 3 & 9 & 35 & 17 & 18 \\
\hline Latvia & 20 & 5 & 5 & 10 & 4 & 5 & 5 & 10 & 40 & 22 & 18 \\
\hline Portugal & 18 & 5 & 4 & 9 & 4 & 5 & 8 & 14 & 45 & 23 & 22 \\
\hline Slovakia & 12 & 5 & 5 & 7 & 4 & 6 & 6 & 10 & 39 & 20 & 19 \\
\hline Spain & 20 & 5 & 5 & 11 & 4 & 10 & 9 & 13 & 53 & 24 & 29 \\
\hline The UK & 16 & 3 & 4 & 9 & 2 & - & - & 8 & 24 & 16 & 8 \\
\hline Total & 213 & 57 & 56 & 100 & 41 & 60 & 63 & 114 & 450 & 230 & 215 \\
\hline
\end{tabular}

Notes: CYP $=$ Children and Young people. $F G=$ Focus Group.

Source: Consortium report: Direct engagement with children and young people. (Ferrer-Fons, Serracant \& Soler-i-Martí 2015a).

\section{School between the Major Domains of Well-being}

To measure children and young people's own assessment of their lives, a number of instruments have been developed over a past decade. The most widely used tool is Huebner's Multi-Dimensional Student Life Satisfaction Scale, which measures wellbeing in five domains: family, friends, school, living environment and self (Huebner, 1991). Focusing on children and young people's everyday lives and their stories constitutes an important dimension of a well-being approach. National datasets of the EU FP7 project "Measuring Youth Well-Being" (MYWeB) made it possible to explore what children and young people prioritize for their well-being. The thematic and contentbased analyses of interviews showed that among the five domains usually determined, children and young people emphasized three leading domains: family, friends and school.

In all of the countries, family is the most important domain for children and young people. Despite the fact that many children have very long days at school and at extracurricular activities, they still connect their well-being first hand with the situation inside the family (Ferrer-Fons, Serracant, \& Soler-i-Martí, 2015a). It was always described by the young people as a core part of their lives and an important domain of their wellbeing. The key factor within family relationships tends to be the relationship children and young people establish with their parents: a positive relationship, in a balanced family environment, tends to be highly valued by children and young people. This means having a good relationship with both of the parents, even if they are separated. Discussions or disagreements are not necessarily disruptive, but a permanent and strong conflict 
is an important negative factor in their lives. Family relationships also involve the relationship parents have between them, i.e., family quarrels, divorces, missing parents, etc. are the main focus of unhappiness among children and young people. Many young people have stressed the pain, discomfort and unhappiness that their parents' quarrels and/or separation have caused them. The young people rate family as the main influence of their lives and describe their families as being a supportive and stable structure, which can offer a positive and constant support: "Family is always important because it's always going to be by your side" (Interview, Ivan, male, 16) (Ferrer-Fons, Serracant, \& Soler-i-Martí 2015b). This domain is not limited to the nuclear family as it also includes the extended family, which includes near relatives as grandparents and cousins.

The domain mentioned as the second most important in most of the countries friends. The interviewees emphasised their need to socialise and the support provided by their peers. For some friends are there to support when problems occur at home, whilst for others it is more about a general support that does not necessarily entail addressing personal problems. This domain tends to be especially valued by teenagers, from whom isolation or problems (quarrels, misunderstandings, etc.) may take on a great importance. For over a third of respondents in Estonia, it was friends and hobby activities or circumstances where they met with friends, which was considered to be the most important aspect of well-being (Taru, Unt, \& Reiska, 2015). The different theoretical dimensions of well-being (happiness, life-satisfaction and psychological well-being) are closely linked to the type of relationships children and young people have with their friends. While these relationships are often the main positive source of this domain, difficulties in these relationships are the most commonly cited sources of unrest.

For the most of interviewees, school is the third of the domains that determines the present quality of life and well-being of children and young people the most. However, the significance of each of domains varied from interview to interview. For some individuals and groups, school and education were the most important domains. Some interviewees in Croatia mentioned school as the second most important domain, for example: "Before, my family was most important to me, and then sports. And now school is in second place." (FG, Loza, female, 14) (Brajša-Žagec, Tadić, Babarović, Franc, Lipovčan, \& Sučić, 2015). Another interviewee explained, “50 \% school, 50 \% family are the most important domains to me." (Interview, Matija, male, 14) (BrajšaŽagec, Tadić, Babarović, Franc, Lipovčan, \& Sučić, 2015). Moreover, school is of particular importance to children with special needs: "The school helps out children who need help-kids, who have some difficulties, like me, they have assistants in the classroom, assistants help us with learning... School sometimes reduces the amount of school work... Also, for example, I can't see what's on the blackboard, so they copy things on paper and give it to me to rewrite it." (Interview, Stjepan, male, 15) (BrajšaŽagec, Tadić, Babarović, Franc, Lipovčan, \& Sučić, 2015). In spite of the absence of one clearly dominant understanding of what was the most important domain, school seemed to be the idea which surfaced in different contexts and meanings.

\section{Well-being at School}

In recent years, well-being of children and young people is described in education policy using conceptual pairings common in political discourse, including wealth, health and happiness. From an adult-centred point of view, the domain school includes factors 
such as access to education, duration of education, status of success according to the quality of education and the contribution of education to adulthood. From children and young people's point of view, the main factors which determine their well-being at school include relationships with teachers, relationships with classmates and schoolmates, learning, academic achievement, stress and anxiety, and democratic school atmosphere.

\section{Relationships with Teachers}

In light of the large amount of time that children and young people spend at school, findings revealed the relationships with teachers as the most significant factor for wellbeing at school. The interviewees expressed different attitudes in relation to the role of teachers for their well-being. Some children had very close contact with their teacher and, thus, they had many good words to say about their teacher. However, the interviewees reported different experiences with teachers, some children stressed that it was vital to have teachers who were kind and did not shout at minor things like leaving books at home or having some little part of homework not done etc. Some children mentioned discrepancies between what teachers said and taught them, and what teachers actually did. For example: "I was at a bar and I saw my teacher smoking. So, she is saying one thing at school, and doing the opposite. That's not very nice... I was bothered by this." (Interview, Matija, male, 14) (Brajša-Žagec, Tadić, Babarović, Franc, Lipovčan, \& Sučić, 2015). Teachers are widely criticized by children because of unfair treatment, which however cannot be discussed properly because of the unequal communicative positions:

I get angry if I experience injustice I really don't like it and this causes many problems. That's why I have 3 (on a scale of 5) for my behaviour, because if I've got a problem I express that 'it's unfair!', because I feel this way and can't prevent this even if I should. For example, if the teacher gives me detention for no reason. For example, last year one of my classmates kicked the dustbin and I was punished, even though I wasn't involved at all. [...] So I argued with the teacher for quite a while, because I felt it was unfair. (Interview, Peter, male, 13) (Sik, 2015).

As this quote shows, teacher-pupil relationships may often become controversial if there is no space for discussing dissent: Peter's angry outburst prevents any rational communication. These "distortions of communication" (Habermas, 1990) no only limit the moral fundaments of a community by damaging democratic relationships, but also result in an alienating or anomic atmosphere. Such distortions of social integration affect many levels of well-being: they not only distort self-respect by undermining a fair institutional culture, but they also burden interpersonal relationships with distrust and cause psychological stress (cf. Sik, 2015).

The basic type of challenge mentioned by several young people is the lack of mutual understanding with teachers.

I don't blame the teachers, because I understand they teach there for 25 years and I'm the $130^{\text {th }}$ stupid kid they have to discipline, but they are fucking uninterested, that's for sure. And they didn't do anything to improve me or our relationship either. With one exception, teachers hated me. So I gradually became disinterested myself and started not to go to school. (Interview, Barnabás, male, 19) (Sik, 2015). 
As the interviewee explains mutual disinterest led in his case to skipping classes and caused serious problems in his career. If not treated properly, the original lack of understanding may result in serious conflicts and even include physical violence. The growing reflectivity and autonomy of young people not only allows for a more critical perspective on the school, but also enables them to confront teacher authority vehemently.

Well, my literature teacher, that was brutal. At the beginning we had a good relationship, but later whenever I entered the class, he asked, 'How is that you're still here?'. I laughed at first, but once he really got going against me. He started to say what a stupid family I have and how could my mother give birth to me and stuff like that. That was when I lost control. I stepped close to him and said, 'Iust repeat what you said!' When he did, I pushed him over the table and threatened that if he ever said anything like that again, I would make him regret it. Then I left. Luckily he didn't report this to the police or anything like that. (Interview, Nándi, male, 18) (Sik, 2015).

As this example shows, young people do not take the authority of teachers for granted, but evaluate them in a very critical way. Also, if a conflict emerges they are ready to defend themselves and fight back. In this context, interviewee's aggression can be interpreted as a desperate attempt to stop and avenge the continuous verbal harassment. Obviously, such longstanding and escalating conflicts have a devastating effect on one's well-being, as they create an extremely stressful and inescapable social environment (cf. Sik, 2015).

A positive and fair attitude is expected from the teacher. It is important for the young people that the teacher listens to them and accepts their viewpoint, devoting sufficient time to explaining the subject, helping them become competent in their subject and treating all the students equally, especially when giving grades.

\section{Relationships with Classmates and Schoolmates}

School was seen to have several positive meanings: it was associated with friends, with class and schoolmates that one meets at school. The interviewees gained a feeling of happiness and pleasure from good, friendly relationships with family members, classmates and teachers, from spending time together, from getting good grades and from good living conditions when nothing worried them or made sad:

Well, perhaps, when everything is good. When, well, everything is fine with me, I talk with everybody, well, on a day I don't have any worries. That's it.

(Interview, Guna, female, 10) (Laudere, Ozolins \& Stasulane, 2015).

Similarly, many children and young people have stressed the importance of having positive, meaningful relationships with their schoolmates and of being accepted; but in most of the countries analysed, children and young people have also mentioned the negative effect on their well-being that isolation can have. School-bullying is broadly perceived as a common event that can have a traumatic effect on those children and young people suffering from it.

On the negative side, school was associated with teasing, nasty nicknames, insults, threats, isolation manoeuvres, rumours and school-bullying. All the respondents would like to see a friendly and united class where it is cheerful, with no conflict or teasing 
among classmates. It transpires from the interviews that teasing and conflicts are more typical in younger classes due to children's behaviour and mental capacity (they are better or worse in their studies), their family situation or the way in which the youngest children try to prove themselves. Bullying was mentioned numerous times by interviewees, some with stronger words than others. For instance, Jane keeps very negative memories of her time in school where she was bullied. She considers bullying to be a cause to her depression:
I absolutely hated [school]. There was a lot ... it was bullying but I wouldn't say it was physical bullying; it was like emotional bullying. I had to go through it and that was crap. It caused a lot of problems with me. That's like one of the root causes of my depression. (Interview, Jane, female, 18) (Ozan, 2015).

\section{Learning}

The interviewees experienced stable well-being when they had a positive learning environment providing challenging, interactive and engaged learning experiences. Several interviewees mentioned that they derived excitement and satisfaction from learning and getting to know new things and new knowledge. Joy of learning new things at school and studying favourite subjects were mentioned as a source of well-being and satisfaction. Young people talked about learning, that they like learning and talked about specific topics they had covered recently which had been fun, for example, learning about planets, doing geometry in mathematics lesson etc. They did distinguish between instrumental value of knowledge and skills and then also mentioned separately that learning new things about subjects that they liked was exciting and interesting for them, that this was a value in itself. "Oh, I get so excited and satisfied when I learn new things about chemistry and biology at school!" (Interview, Eve, female, 14) (Taru, Unt, \& Reiska, 2015). This girl also said that she wanted to specialise in gene-technology in future and that she also needed to develop logical reasoning. Another girl (Interview, Linda, female, 15) (Taru, Unt, \& Reiska, 2015) said that she was very interested in knowing more about languages and several other subjects and that she studied those subjects with great interest. These themes did not come to the fore immediately; they were not mentioned among the first things. Besides, these themes were not mentioned by everybody - actually the majority of interviewees did not mention such experiences or such drive for self-improvement, self-actualisation and self-realisation. Therefore, it looks as if satisfaction derived from self-actualisation and self-realisation is important for relatively few. Interviewees who considered self-development, self-actualisation and self-realisation to be important were similar with other interviewees in other respects. This suggests that self-actualisation comes in addition to usual and normal aspects of life that were mentioned by other people. It does not replace more common experiences but it complements them or adds to them, adding details and making the mosaic more varied and more complex (cf. Taru, Unt, \& Reiska, 2015).

For some interviewees, school was also associated with preparation for the future, i.e., for university studies, choosing a profession, finding a job that earns good money and brings pleasure.

Education is perceived by the children interviewed as necessary for obtaining a good job in the future. They associate education with job opportunities and consequently future quality of life. This link is very clearly understood by all of the interviewees: 
You get to learn new stuff that you'd never heard of and so you get a good education if you want to work in somewhere that's a good place to work at. (...) Because then you don't have a miserable life because some people they don't really pay attention in school and then when they grow up they have a really, really miserable life. (Interview, Grace, female, 12) (Ozan, 2015).

The respondents considered that if they were studying, attending school, and discovering a lot of new and interesting things were important and crucial, this was a guarantee for a successful future career, for well-being and for a good and well-paid job as well as personal development: "If you're not in school, you won't know anything!" (Interview, Kārlis, male 10) (Laudere, Ozolins, \& Stasulane, 2015).

In many cases, however, learning appeared as the framework of their lives more than as a direct source of well-being. Among full-time students, their studies have a major importance, even among those who declare not to be interested in them. Studies rule their daily lives, both during school time and their leisure time (homework, exams, etc.), and they condition the people they meet and make friends with and shape many of their daily activities and conversations.

\section{Academic Achievement}

The academic achievement at school also plays a significant role in overall wellbeing. Even though not every child sensed the importance of school performance clearly, most of them referred to the feedback of the school as a key component of their everyday well-being. School is the main field of productivity in children's life, where their individual capability is measured by the community. Consequently, they internalize the measures and evaluation of the school, culminating in the fetishizing of grades. Good grades are uncritically perceived as a sign of worthiness, while bade grades as a sign of incompetence. Being the primary source of self-esteem, school success expressed in grades plays a distinctive role in subjective well-being (cf. Sik, 2015).

The school is a distinctive terrain of potential difficulties and challenges, and basically personal educational failures are mentioned by children:

Q: You mentioned your parents are strict concerning your grades.

A: Well, they don't like average or below average grades.

Q: What do you mean?

A: Well, they accept if I get a 3 (on a scale of 5), but not for every subject. They say I have the brains, but I'm lazy.

Q: Do you agree with this?

A: Partly yes, but frankly I can't learn things I'm not interested in at all. Let's take history: I'm a stable 3, sometimes I aim for a 4, but I'm not interested at all... And history is unfortunately particularly important for my father. (Interview, Klara, female, 13) (Sik, 2015).

As Klara expresses, grade quality is a social construct based on the expectations of parents, teachers and children. In many cases, these expectations are in conflict, which results in either actual social conflicts or internalized conflicts resulting in anxiety. In both cases, well-being is damaged (cf. Sik, 2015).

While for children school performance is something externally driven, for most young people it becomes important as a means to realise their goals. Accordingly, having 
good grades is not a goal in itself anymore, but an indicator of being on the right track towards other goals. Also, young people reflect on a broader context of education, including its price and consequences for their job opportunities.

The school children emphasized that they were learning for themselves: "It's like this, what your education is like, where you'll work, it depends on this. One of the achievements you'll have." (Interview, Lauma, female, 10 years old) (Laudere, Ozolins, \& Stasulane, 2015). Obviously, parents and teachers are happy when children do well and achieve in your studies. However, the school children admitted that it is possible to study and develop personality and that it is an important measurement of well-being. School is rated highly in the interviews - you gain a lot which is of use in your future adult life there. Young people attend school mainly to gain knowledge, developing themselves in this way and laying the foundations for a successful future (studies at university and a good career), and to have a good time forming friendly relationships and socializing with their peers. In less common situations, going to school is considered unnecessary and is done for the sake of the parents:

School isn't useful. It's education, and you can gain education at work, but well... The only reason why I try to do well is simply so that my parents would be proud of me. That's the only reason. (Interview, Valdis, male, 15) (Laudere, Ozolins, \& Stasulane, 2015).

\section{Stress and Anxiety}

Nevertheless, school was associated with stress and anxiety. One of the most widespread complaints was about a large volume of unnecessary information, though in some cases this was also valued positively, explaining that in choosing what to study, one could learn to select priorities: "I like coming to school, I like learning. Sometimes I don't like the senselessness, as I intensely feel that some things are completely useless for my future, that it's terrible how very unnecessary this is, and how aware I am of it." (Interview, Liene, female, 18) (Laudere, Ozolins, \& Stasulane, 2015). School can become a very stressful environment for a child who did not acquire what was taught in class:

If we don't have a test on that day I like [school], but if we do have a test on that day I go all stressed out and all that because... sometimes the work is really hard and you don't get it and when the teacher explains it to you, you don't really get it and when it comes to do the homework you're like I don't know this. (Interview, Grace, female, 12) (Ozan, 2015).

The strict school programme and extra-school activities for the adolescents mean that they do not have enough free time to entertain themselves and rest. They feel pressured by society which "does not accept mediocrities" (FG, Spyros, male, 15) (Koronaiou, Alexias, Chiotaki-Poulou, Sakellariou, \& Vayas, 2015) and expects too much of them.

Young people were feeling exhausted and they expressed their will to finally have a stable national curriculum and examination procedure, with less study hours and more opportunities for leisure time. In addition, they said that they had many extraschool activities and even though most of them were satisfied with that, they also felt the pressure from their social environment and especially their family that they had to achieve high goals either at sports or in learning foreign languages to mention some of 
them (cf. Koronaiou, Alexias, Chiotaki-Poulou, Sakellariou, \& Vayas, 2015). Young teenagers were more anxious about the future. The educational setting appears to favour stress and anxiety for most students. They expressed their anxiety regarding their ability to pass the national exams for the university and what they should do if they fail (cf. Koronaiou, Alexias, Chiotaki-Poulou, Sakellariou, \& Vayas, 2015). The young people interviewed described how tests, assignments, exams were associated with some level of stress:

I mean, honestly during this period where we had the mock [exam] I was, you know, out of a lot of sleep and really hectic it was, yes. (...) there is quite a lot of work, I mean, even the preparation for the real exams is just itself really tiring and when the real exams come it's almost as if though you've forgotten all the things that you need to know because of the stress that you've gone through. (Interview, Adnan, male, 16). (Ozan, 2015).

School anxiety is mentioned by a surprisingly high number of the interviewed children, which indicates that it is a general problem. The different levels of anxiety are a common psychological problem among children and young people oriented to good school performance: they specifically worry about good grades, show signs of depressed helplessness and try to escape from responsibility. These different reactions express the potential psychological disorders originating from school pressure, which seriously damage children's well-being (cf. Sik, 2015). Exams or homework are fundamental parts of children and young people's lives and their worries, stressful situations or expectations are very often related to their studies. In many cases, this has a direct effect on their well-being: academic results, the pressure of exams, the boredom of routine or the lack of interest in certain subjects was mentioned by interviewees as sources of satisfaction and dissatisfaction.

\section{Democratic School Atmosphere}

While the primary purpose of school is the academic development of children and young people, it affects their civic engagement and social development. Schools also serve as the first institutions with which children get in contact. In this sense, they are the sources of the first impressions concerning public institutions. Such experiences may result in a trustful attitude or disappointment.

Q: If you have some problem here at school, do you feel that your voice is heard?

A: Well, I'm involved in the student parliament where we can express our opinions. But it doesn't always have an effect.

Q: I see... And what are your experiences?

A: Well, we discuss issues like the new decorations. Sometimes unfortunately the bigger students don't inform us about the gatherings. But the teacher told them already that it's not fair. (Interview, János, male, 12) (Sik, 2015).

An attempt can be made to establish a democratic school atmosphere where teachers participate in communication oriented to mutual understanding and democratic socialization occurs. Only such a climate is capable of grounding a trustful relationship with public institutions, which is an important aspect of feeling secure (cf. Sik, 2015). 
The young people mentioned that despite the fact that they were asked to express their opinions during lessons at school or to reveal their position on some issue, these opinions were not always respected, and this was influenced not only by the theme being discussed but also by the teacher's attitude. Such disconnectedness results in a more critical relation to school, which however does not lead to any sort of civic action because of inappropriate institutional culture.

Q: What do you mean by hushing up?

A1: Well when someone does something wrong, but it won't have any consequence. (Focus Group, Edina, female, 16).

Q: And this happens at school?

A1: Yeah.

A2: It happens often. (Focus Group, Janó, male, 18).

Q: So why don't you raise your voice?

A1: Because then it will be a problem that we are resisting.

A2: We can pretend to be a freedom fighter, but we won't be able to accomplish anything.

A1: A student is always inferior compared to a teacher. (Sik, 2015).

As these students explain, even if they are aware of injustice in their school, they do not feel they have a chance do anything about it. Such an experience of powerlessness is an important factor of the potential threats of satisfaction as it indicates long-term institutional expectations (cf. Sik, 2015). While school is the primary institution for evaluating worthiness and determining social mobility, it is also an agency of discipline and punishment provoking resistance and revolt. Such instrumental and disciplinary functions make school another key dimension of the constitution of subjective wellbeing: school failures and dysfunctions are amongst the most important sources of anxiety, low self-esteem or deviant behaviour patterns.

\section{Conclusions}

The present paper has investigated the contribution of school contextual factors to children and young people's well-being. Despite economic, social, cultural and ethnic differences between countries, project results have indicated a six-factor model that comprises relationships with teachers, relationships with classmates and schoolmates, learning, academic achievement, stress and anxiety, and democratic school atmosphere.

The fieldwork conducted in Croatia, Estonia, Georgia, Germany, Greece, Hungary, Latvia, Portugal, Slovakia, Spain and the United Kingdom (October 2014 - January 2015) reveals that the perception of well-being is greatly transformed as children become young people. Children have more difficulty to explain concepts related to well-being so family, school or peer environment appear to be very important. As they identify more easily with their parents and teachers' perspective, family tensions or institutional injustices have a direct effect on the quality of their well-being. Moreover, children seem to have a less elaborated sphere of autonomy. Free-time activities that satisfy their desires are not linked to the process of identity construction, but remain merely as an instrument for having fun.

In contrast, young people have a more reflective relationship towards their family, school or peer environment. As they have already developed some autonomy and an 
independent perspective, they evaluate their broader context, potentials and responsibilities and initiate actions oriented to resolve potential problems or to achieve goals. In the reports, the experience of being active in social and political groups of different types appears to be an important factor affecting the perception and elaboration of discourse among young people, giving a more social and community dimension to the concept.

The study indicates the positive benefits of a contextualized approach to well-being that takes into account the subjective viewpoint of children and young people rather than merely objective data. The findings from the research conducted during the MYWeB project suggest that educational spaces could take a more significant role in promoting well-being of children and young people. The educational community mainly thinks of pupils' well-being in material and organisational terms, but children and young people are more likely to enjoy life and school, and be successful and engaged in their learning. The education system must rebalance academic learning and emotional well-being; this is what children and young people need.

The findings of the research (specific features of the factors determining children and young people's well-being) reveal that a school in particular and the society in general nowadays have mainly been characterized by unsustainability. Therefore, definite actions and reorientation activities leading to sustainability are recommended. The analysis of the nature of the phenomenon of well-being, including various attitudes and relationships in the organization of education environment, testifies to the necessity of the improvement of the education system via addressing the issue of the quality and sustainability of education in its wider perspective.

\section{Acknowledgements}

The research leading to these findings has received funding from the European Union Seventh Framework Programme project "Measuring Youth Well Being” (MYWeB) under Grant Agreement number FP7-613368.

\section{References}

Biswas-Diener, R., Kashdan, T. B., \& King, L. A. (2009). Two traditions of happiness research, not two distinct types of happiness. The Journal of Positive Psychology, 4(3), 208-211.

Brajša-Žagec, A., Tadić, M., Babarović, T., Franc, R., Lipovčan, L. K., \& Sučić, I. (2015). Country level reports on interviews and focus groups from delivery partners: Croatia. Unpublished.

Compton, W.C., Smith, M.L., Cornish, K.A., \& Qualls, D.L. (1996). Factor structure of mental health measures. Journal of Personality and Social Psychology, 71(2), 406-13.

Diener, E., \& Lucas, R.E. (1999). Personality and subjective well-being. In D. Kahneman, E. Diener, \& N. Schwarz (Eds.), Well-Being: The Foundations of Hedonic Psychology (pp. 213-229). New York: Russell Sage Found.

Ferrer-Fons, M., Serracant, P., \& Soler-i-Martí, R. (2015a). Consortium report: Direct engagement with children and young people. Unpublished. 
Ferrer-Fons, M., Serracant, P., \& Soler-i-Martí, R. (2015b). Country level reports on interviews and focus groups from delivery partners: Spain. Unpublished.

Fredrickson, B. L., \& Losada, M. F. (2005). Positive affect and the complex dynamics of human flourishing. American Psychologist, 60(7), 678-686.

Habermas, J. (1990) Moral consciousness and communicative action. Cambridge, MA: MIT Press.

Huebner, E. S. (1991). Further validation of the students' life satisfaction scale: The independence of satisfaction and affect ratings. Journal of Psychoeducational Assessment, 9(4), 363-368.

Huppert, F. A., \& So, T. T. C. (2013). Flourishing across Europe: Application of a new conceptual framework for defining well-being. Social Indicators Research, 110(3), 837-861.

Diener, E., Suh, E. M., Lucas, R. E., \& Smith, H. E. (1999). Subjective well-being: Three decades of progress. Psychological Bulletin, 125(2), 276-302.

Keyes, C. L., Shmotkin, D., \& Ryff, C. D. (2002). Optimizing well-being: The empirical encounter of two traditions. Journal of Personality and Social Psychology, 82(6), 1007-1022.

King, L. A., \& Napa, C. K. (1998). What makes life good? Journal of Personality and Social Psychology, 75(1), 156-65.

Koronaiou, A., Alexias, G., Chiotaki-Poulou, E., Sakellariou, A., \& Vayas, G. (2015). Country level reports on interviews and focus groups from delivery partners: Greece. Unpublished.

Laudere, M., Ozolins, G., \& Stasulane, A. (2015). Country level reports on interviews and focus groups from delivery partners: Latvia. Unpublished.

McGregor, I., \& Little, B. R. (1998). Personal Projects, Happiness, and Meaning: On Doing well and being yourself. Journal of Personality and Social Psychology, 74(2), 494-512.

Ryff, C. D., \& Singer, B. (2000). Interpersonal flourishing: A positive health agenda for the new millennium. Personality and Social Psychology Review, 4(1), 30-44.

Ozan, J. (2015). Country level reports on interviews and focus groups from delivery partners: United Kingdom. Unpublished.

Proctor, C., Tweed, R., \& Morris, D. (2014). The naturally emerging structure of wellbeing among young adults: "Big two" or other framework? Journal of Happiness Studies, 16(1), 257-275.

Rees, G., Bradshaw, J., Goswami, H., \& Keung, H. (2010). Understanding children's well-being: A national survey of young people's well-being. London: The Children's Society.

Ryan, R. M., \& Deci, E. L. (2000). Self-determination theory and the facilitation of intrinsic motivation, social development, and well-being. American Psychology, 55(1), 68-78.

Ryan, R. M., Huta, V., \& Deci, E. L. (2006). Living well: A self-determination theory of eudaimonia. Journal of Happiness Studies, 9(1), 139-170.

Ryan, R. M., \& Deci, E. L. (2001). On happiness and human potentials: A review of research on hedonic and eudaimonic well-being. Annual Review of Psychology, $52,141-66$.

Ryff, C. D., \& Singer, B. (1998).The Contours of Positive Human Health. Psychological Inquiry, 9(1), 1-28. 
Ryff, C. D. (1989). Happiness is everything, or is it? Explorations on the meaning of eudaimonic well-being. Journal of Personality and Social Psychology, 57(6), 10691081.

Ryff, C. D., \& Keyes, C. L. M. (1995). The structure of psychological well-being revisited. Journal of Personality and Social Psychology, 69(4), 719-727.

Salite, I. (2015). Searching for sustainability in teacher education and educational research: Experiences from the Baltic and Black Sea Circle Consortium for educational research. Discourse and Communication for Sustainable Education, 6, 21-29.

Salīte, I., Drelinga, E., Iliško, Dz., Oḷehnoviča, E., \& Zariņa, S. (2016). Sustainability from the transdisciplinary perspective: An action research strategy for continuing education program development. Journal of Teacher Education for Sustainability, $18(2), 135-152$.

Sik, D. (2015). Country level reports on interviews and focus groups from delivery partners: Hungary. Unpublished.

Taru, M., Unt, M., \& Reiska, E. (2015). Country level reports on interviews and focus groups from delivery partners: Estonia. Unpublished.

Van der Deijl, W. (2017). Are measures of well-being philosophically adequate? Philosophy of the Social Sciences, 47(3), 209-234.

Correspondence concerning this paper should be addressed to Dr. Anita Stasulane, Daugavpils University, Vienības iela 13, Daugavpils, Latvia, LV-5401. Email: anita.stasulane@du.lv 